chapter, which is based on a speech, gives such meagre information about the many people named that I can only conclude that either they were present at the speech or were known to those who were.

Only a couple of the 30 -odd essays deal specifically with the unification of the weak and electromagnetic forces. And only a handful discuss those of the author's predictions that turned out to be correct, such as the existence of the 'charmed quarks' that give the book its name. There seems to be only one set of laws of nature, and there are many fascinating possibilities that nature appears to have ignored. As most creative scientists do, Glashow has stumbled upon many more of the latter than of the former. But unlike many of his colleagues, he is ready to discuss them both. An example of an idea whose experimental verification nature seems mysteriously to be postponing is the 'grand unification' of (almost) all known forces that, as Glashow admits, has so far turned out to be like the Holy Roman Empire, that is, neither grand nor unified.

The Charm of Physics contains autobiographical material, occasional attempts at

\section{Legal thinking}

Andrew Grubb

Family Rights: Family Law and Medical Advances. Edited by Elaine Sutherland and Alexander McCall Smith. Edinburgh University Press: 1991. Pp.135. £25. (Distributed in the US by Columbia University Press, \$39.)

DURING the past decade there has been a remarkable growth of interest in medical law. One of the principal areas of study and research for medical lawyers has been the legal regulation of decision-making about medical treatment and the family: decisionmaking concerning when not to have a child (contraception and sterilization); when to create a child (in vitro-fertilization treatment and surrogacy); when to end a pregnancy (abortion and selective reduction); what controls to impose on a pregnant woman out of a concern for her unborn child (paternal injunctions prohibiting abortion, courtordered caesarian sections) and, finally, what treatment an ill child should receive (withholding life-saving treatment from, for example, handicapped babies).

There are few, if any, easy solutions to many of these areas of public controversy. Two principal questions arise: first, should the law regulate the particular area of decision-making and second, if so, what should that regulation be? Family Rights is a volume of seven essays, predominantly written by academic lawyers, which addresses many of the legal dilemmas that modern medicine has created for society.

As the essays illustrate, the law is a potent regulatory force in policing the moral dilem- poetry, blood-chilling views on nuclear holocaust and other self-imposed threats to mankind, fascinating recollections of the discovery and successive theories of chemical elements, planets, galaxies, pulsars and quarks. Glashow also treats us to delightful introductions to various aspects of mathematics, chemistry, physics and cosmology, including instructions on how to find our distant neighbours, the 'little green people' that, the author elaborately argues, live in large numbers elsewhere in our galaxy. The style is light and humorous, except in those essays that deal with more serious issues, such as the likely fate of mankind or, perhaps more immediate, the future of science and technology - and of education in general in countries such as Britain or the United States.

Glashow's book, and he himself, are both deep and superficial, serious and hilarious, thoughtful and scatter-brained and much more besides. Although they defy summary, they truly deserve attention.

Alvaro De Rujula is in the Theory Division, CERN, CH-Genève 23, Switzerland.

mas of family decision-making, and rightly so, given the important human interests that are in play. But the law is often slow at providing a response to a new development. Judges can only deal with cases that are brought before them and Parliament may not want to intervene where a morally 'hot potato' exists. As Bernard Dickens shows, until recently the English common law provided almost no mechanism for the regulation of modern reproductive technology except, perhaps, in relation to status questions of parenthood based upon what some would call the approach of a by-gone era. Fortunately, after six years of vacillation, Parliament passed the Human Fertilization and Embryology Act 1990, which provides a comprehensive regulatory framework for modern reproductive technologies. But this is not always the case. Surrogacy, for example, remains unregulated in England despite the 1990 Act. Could it be, as Sheila McLean suggests in her essay, that the moral controversy has not been explored sufficiently for politicians to make up their minds? Certainly, as she points out, few can ignore the commercial element which is often present and which produces such strong feelings of revulsion.

Sometimes judges defer to the legislature because of the controversial nature of any law they would develop. Hence, as Elaine Sutherland catalogues, English judges have been reluctant to become involved in regulating decisions concerning pregnant women. Courts have refused injunctions to fathers who are seeking to prevent an abortion and have also refused to exercise their protective jurisdiction over an unborn child when an attempt is made to protect it from its mother's (alleged) dangerous conduct. The theoretical difficulties of intervening - dis- regard of the woman's right of autonomy and the practical problems of enforcement conspire against judicial intervention. Sutherland argues in favour of some legal intervention. Not everyone would agree with this approach, although there is a growing body of persuasive authority in the United States which would support it.

By contrast, in a number of areas judicial intervention has been accepted often out of a perceived need to protect an individual; sterilization of mentally handicapped girls and women, for example. Similarly, judges are willing to override parental decisions in relation to nontreatment of their children, in particular handicapped babies, if they consider the parents' decision not to be in the child's best interests. Douglas Cuisine and David Meyers examine the judicial approaches to these two areas of family decision-making.

Faced with this largely interventionist judicial attitude, it is left to Sandy McCall Smith to challenge its basis and to sound a note of caution. Should the courts 'secondguess' parental decisions or should they leave them to those whom it is usually accepted best understand the needs of their children? This is a fundamental question. It features, rightly, in the first chapter. But on the basis of the English case law, McCall Smith has really lost his argument: courts do, on the whole, intervene as protectors of a child's best interests.

Family Rights will provide the general reader with a reasonably accessible account of current legal thinking. There is undoubtedly more to come from the courts (and Parliament) in the future. The book deserves to be widely read and will set the scene for the public debate, which has really only just begun.

Andrew Grubb is at the Centre of Medical Law and Ethics, King's College London, Strand, London WC2R $2 L S$, UK.

\section{New in paperback}

The paperback edition of Hormones: From Molecules to Disease edited by Etienne-Emile Baulieu and Paul A. Kelly (for review see Nature 351, 362; 1991) is available from Chapman and Hall at a price of $£ 47.50$ $\$ 62.50$.

- For an introduction to polymer science suitable for undergraduate courses, see the second edition of Polymers: Chemistry \& Physics of Modern Materials by J. M. G. Cowie. Published by Blackie/Chapman and Hall, price is $£ 19.95$.

- Sequence Analysis Primer edited by Michael Grobskov and John Devereux provides a useful introduction to computerized sequence analysis in biotechnological research. The book is published by Stockton Press at $\$ 39.95$.

Those interested in body size, life histories and evolutionary biology in general should look out for The Allometry of Growth and Reproduction by M. J. Reiss. The book is published by Cambridge University Press at a price of $£ 12.50, \$ 19.95$. 